\title{
Ramadan, TURKMI, REALITY HF, and so on...
}

Fasting is one of the most important rituals of Islam and, currently, we are in the month of Ramadan. Notably, the Turkish Society of Cardiology has prepared a consensus report. The main objective of this report is to summarize the current literature on Ramadan fasting and discuss the potential beneficial or adverse effects on patients with or at risk of cardiovascular diseases. The secondary aim is to propose an evidence-based suggestion regarding who is or is not eligible for fasting. This report will help physicians answer their patients' questions regarding fasting.

"Time delays in each step from symptom onset to treatment in acute myocardial infarction: results from a nation-wide TURKMI Registry" is another part of this important study carried out by Erol et al. from Turkey. It gives valuable data on this issue.

"Resting heart rate and real-life treatment modalities in outpatients with left ventricular systolic dysfunction study: a multicenter, prospective, observational, and national registry" (REALITY HF) discusses the importance of heart rate in these special conditions. Çavuşoğlu et al. from Turkey evaluates data of several patients.

Sevinç Şengül et al. from Turkey aimed to define the clinical characteristics, treatment strategies, and long-term course of pediatric patients who were diagnosed with sustained ventricular tachycardia according to the clinical category. The results cover 10 years of experience.

Interestingly, Zhang and He from China investigated the association of circulating miR-660-5p levels with the no-reflow phenomenon (NRP) in patients with ST-elevation myocardial infarction undergoing primary percutaneous coronary intervention. They suggest that miR-660-5p could be a biomarker for NRP.

“Elabela as a novel marker: well-correlated with WIfl amputation risk score in patients with lower extremity arterial disease" is a paper by Kaplan et al. from Turkey revealing the possible relationship of serum Elabela levels with wound, ischemia, and foot infection score, which is a new amputation risk score in lower extremity arterial disease.

Kisheva and Yotov from Bulgaria studied risk factors for recurrence of atrial fibrillation in detail.

Evaluation of arterial stiffness and hemodynamic parameters in patients with a supraphysiological estrogen level owing to in vitro fertilization with controlled ovarian hyperstimulation is a rather different study by Akçay and Özdemir from Turkey. The results will be of interest to our readers.

Furthermore, many case reports and letters to the editor, including one that is remarkable and related to our difficult times (Medicine in Philately-Masks), and e-pages.

I hope this issue will be of interest to our readers.

\section{Prof. Dr. Çetin Erol \\ Editor-in-Chief \\ Ankara-Turkey}

Address for Correspondence: Prof. Dr. Çetin Erol, Ankara Üniversitesi Tıp Fakültesi, İbn-i Sina Hastanesi, Kardiyoloji Anabilim Dalı, Ankara-Türkiye

Phone: +90312310 3333 /27 79 E-mail: ctnerol@yahoo.com 